the uterus must be emptied. Delivery of the infant improves maternal circulation and increases venous return. After delivery pressure in the inferior vena cava promptly returns to prepregnancy values ${ }^{8}$ and cardiac output increases by $60-80 \%$ of prepregnancy values."

Urgent operation is critical to mother and baby. Anoxia causes irreversible brain damage in an adult in three to four minutes, and hypoxia develops sooner in pregnancy. ${ }^{10}$ Unfortunately, the period of cardiac arrest in our patient was at least 15 minutes, and the neurological sequelae showed the effect of such anoxia.

Review of published reports shows that $70 \%$ of neonatal survivors delivered up to five minutes after maternal death were normal." Weil and Graber reported on a normal neonate delivered after 15 minutes of unsuccessful cardiopulmonary resuscitation. "In our case the infant, despite anoxia of more than 15 minutes and no detectable heart rate at birth, survived without any neurological problems. Although caesarean section is done primarily for the mother's benefit, it may also help the baby's chance of survival. Cardiopulmonary resuscitation must be continued throughout the caesarean section to maintain blood flow as this increases the chance of a successful maternal and neonatal outcome. ${ }^{12}$

Amniotic fluid embolism is rare but has a mortality of over $80 \% .{ }^{1314}$ It is associated with increasing age and parity and with short, tumultuous labours, but it rarely occurs before the onset of labour. Treatment is threefold: control of the bleeding diathesis, which occurs in $30 \%$ of patients; replacement of blood; and, most importantly, cardiopulmonary resuscitation. Amniotic fluid embolism can be diagnosed in survivors by the finding of elements of amniotic fluid in the maternal circulation.'

Recent guidelines from the Royal College of Physicians outline the difficulties in resuscitating pregnant women and support the use of emergency caesarean section as part of the procedure. ${ }^{16}$ We agree with other authors ${ }^{312}$ that if the patient does not respond after five minutes of cardiopulmonary resuscitation, taking caval compression into account, then a caesarean section should be performed, cardiopulmonary resuscitation being maintained throughout and after delivery. Such aggressive management can further decrease maternal mortality.

1 Turnbull AC, Tindall VR, Robson G, Dawson IMP, Cloake EP, Ashley JSA. Report on confidential enquiries into matemal deaths in England and Wales 1979-1981. London: HMSO, 1986. (Department of Health and Social Security. Report on health and social subjects No 29.

2 Marx GF. Cardiopulmonary resuscitation of late pregnant women. Anesthesiology 1982;56:156.

3 Katz VL, Dotters D, Droegemueller W. Perimortem cesarean delivery. Obstet Gvnecol 1986;68:571-6.

4 Ueland K, Novy MJ, Peterson EN, Metcalfe J. Maternal cardiovascular dynamics. IV. The influence of gestational age on the maternal cardiovascular response to posture and exercise. Am J Obstet Gynecol 1969;104: $856-64$

5 Kasten GW, Martin ST. Resuscitation from bupivacaine induced cardiovascular toxicity during partial inferior vena cava occlusion. Anesth Analg 1986:65:341-4

6 De Pace NL, Betesh SS, Kolter MN. "Post mortem" cesarean section with recovery of both mother and offspring. FAMA 1982;248:971-97.

7 Rees GAD, Willis BA. Resuscitation in late pregnancy. Anaesthesia 1988;43: $347-9$

8 Kerr MG, Scott DB, Samuel E. Studies of the inferior vena cava in late pregnancy. Br.Med 7 1964;i:532-3.

9 Ueland K. Hansen JM. Maternal cardiovascular dynamics. III: labour and delivery under local and caudal analgesia. Am $\mathcal{f}$ Obstet Gynecol 1969;103: 8-17.

10 Archer GW, Marx GF. Arterial oxvgen tension during apnoea in parturient women. Br $\mathcal{F}$ Anuesth 1974;46:358-60

11 Weil AM, Graber V'R. The management of the near-term pregnant patient who dies undelivered. A $m$ f Obst Gynecol 1957;73:754-8.

12 Weber CE. Post mortem cesarean section: review of the literature case reports. Am 7 Obstel Gynecol 1971;110:158-65.

13 Killam A Amniotic fluid embolism. Clin ()hstet (ivnecol 1985;28:32-6.

14 Morgan M. Amniotic fluid embolism: review. Anaesthesia 1979;34:20-32.

15 Masson R, Ruggieri J, Siddiqui M. Amniotic fluid embolism: definitive diagnosis in a survivor. Am Rev Respir Dis 1979;120:187-92.

16 Hoffenberg R, Evans TR, Adgey J, et al. Resuscitation from cardiopulmonary arrest: training and organisation. F $R$ Coll P'hysicians Lond 1987;21:175-81.

Accepted 20 April 1988.
Department of Child

Health, Queen's Medical

Centre, Nottingham

NG7 2UH

Angus Nicoll, MRCP, lecturer

\section{Keyworth, Nottingham} NG125JU

Douglas Jenkinson, FRCGP, general practitioner and lecturer in general practice

Correspondence to: Dr A Nicoll, London School of Hygiene and Tropical

Medicine, London WC1E 7HT.

\title{
Clinical Algorithm
}

\section{Decision making for routine measles/MMR and whooping cough immunisation}

\author{
Angus Nicoll, Douglas Jenkinson
}

In the United Kingdom the uptake of vaccination against measles and whooping cough is low. Uptake rates for measles vaccination are comparable with those in west Asian countries and those for whooping cough vaccination with those in African countries rather than those in other industrial countries. ${ }^{\prime}$ The introduction of a combined measles-mumps-rubella (MMR) vaccine in October this year will give the Department of Health and Social Security an opportunity to mount a major promotional campaign to try to counter this low uptake rate.

The problems underlying this failure to vaccinate are complex, reflecting professional as well as public attitudes. All the evidence is, however, that enthusiastic, well organised practitioners and health districts can override such factors and at least approach ${ }^{2-4}$ national targets, 'even in areas of deprivation. ${ }^{+6}$ Health care professionals advising parents face the problem that much false information exists about contraindications and that individual circumstances are sometimes complex.

To aid the promotion of vaccination we have prepared annotated algorithms to guide in making decisions on vaccinating individual children. They also estimate the maximum uptakes given the updated contraindications. ${ }^{8}$

1 Unicef. The state of the world's children 1988. Oxford: Oxford University Press, 1988.

2 Nicoll A, Hutchison T, Polnay L, Roden D. A training procedure for immunisation. Health Trends 1987;19:19-24.

3 Walker D, Carter H, Jones IG. Measles, mumps, and rubella: the need for a change in immunisation policy. Br Med $\mathcal{J} 1986 ; 292: 1501-2$.

4 James J, Clark C, Rossdale $M$. Improving health care delivery in an inner city well baby clinic. Arch Dis Child 1986;61:630.

5 Begg NT, Noah ND. Immunisation targets in Europe and Britain. Br Med $\mathcal{F}$ 1985;291:1370-1.

6 Alberman E, Watson E, Mitchell P, Day S. The development of performance and cost indicators for pre-school immunisation. Arch Dis Child 1986;61: 251-6.

Nicoll A. Contraindications to whooping-cough immunisation-myths or realities. Lancet 1985 ;i:679-81.

8 Joint Committee on Vaccination and Immunisation. Immunisation against infectious disease. London: Department of $\mathrm{Health}$ and Social Security, 1988. ull D. Interpretation of the contraindications 10 whooping cough vacination. Br Med F 1981;283:1231-3.

10 Campbell AGM. Measles immunisation: why have we failed. Arch Dis Child $1983: 58: 3-5$.

1 Adaje N, Azad A, Foster M, Marshall WC, Dunn H. Measles serology in children with a history of measles in early life. Br Med $\mathcal{F} 1983 ; 286: 1478$.

12 Jelley DM, Nicoll AG. Pertussis: what percentage of children can we immunise? Br Med F 1984;288: 1582-4.

13 Stetler HC, et al. History of convulsions and use of pertussis vaccine. f Pediatrics 1985;107:175-9.

14 Taylor DJ, Howie PW, Davidson J, Davidson D, Drillien CM. Do pregnancy complications contribute to neurodevelopmental disability? Lancet 1985; $713-6$ 


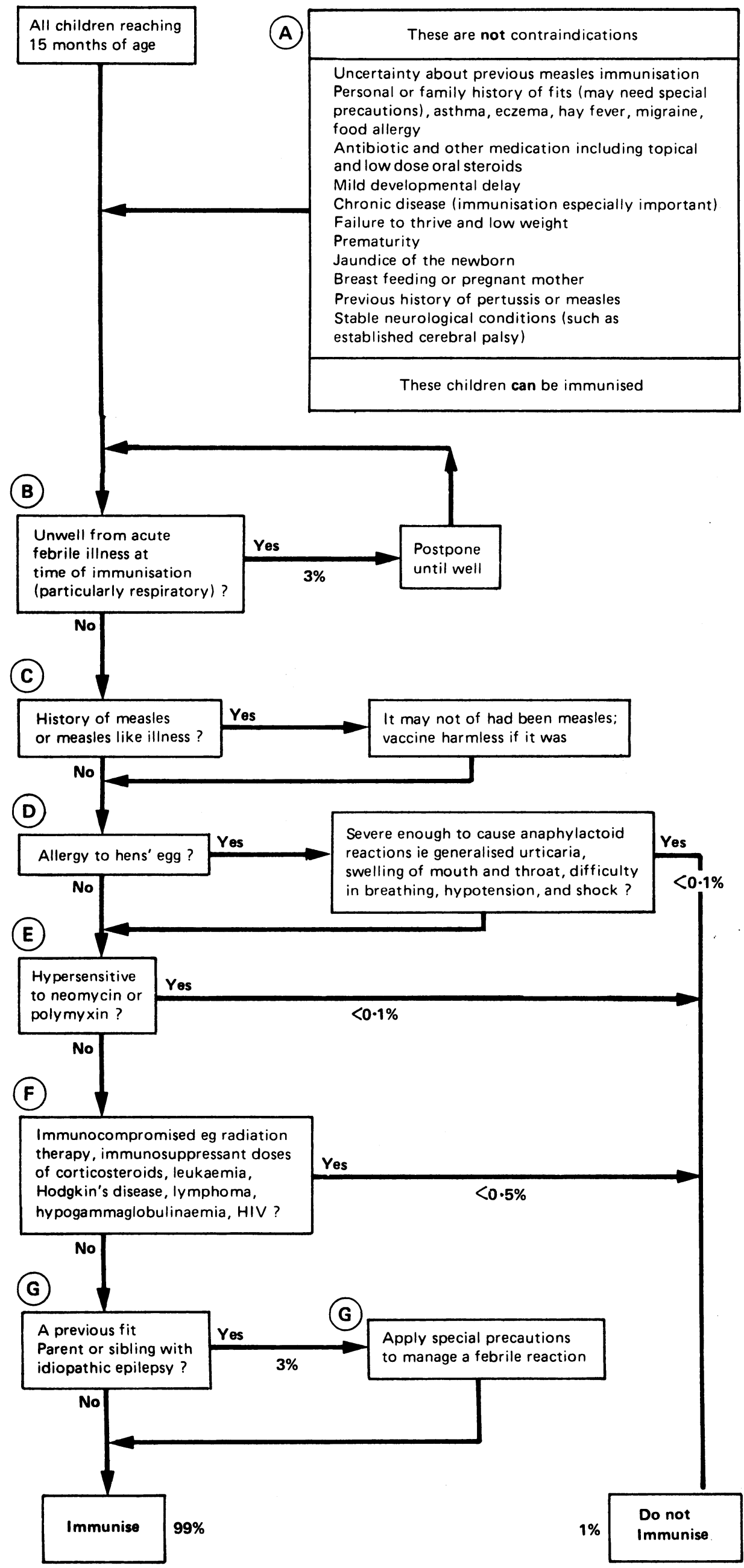

(A) All of these reasons have been presented to us as contraindications. None of them are, though some have been so in the past. They represent mythical contraindications ${ }^{7910}$ by which many children are incorrectly denied protection.

(B) Children are sometimes thought to be too ill for immunisation. Children starting an acute febrile illness should have their immunisation deferred. ${ }^{8}$ To estimate the number of children affected we monitored three routine child health clinics (one in general practice, two organised by the health authority) during January to March 1986. On average $3 \%$ of children presenting for immunisation were too ill on the day.

(C) Many cases of measles, even when diagnosed by a doctor, prove not to have been so on serological testing; this is particularly so in younger children."

(D) The true incidence of severe allergy to hens' eggs is unknown. Certainly it is extremely rare-a reasonable estimation is under $0.1 \%$ (J Soothill, personal communication).

(E) Hypersensitivity to either neomycin or polymyxin is usually of a mild delayed form not causing severe problems in immunisation and is extremely rare in community and hospital paediatric experience (Committee on Safety of Medicines, personal communication).

(F) These conditions are all uncommon and are unlikely to affect more than $0.5 \%$ of a child population. Killed vaccines and toxoids may be given safely. Nevertheless, such children may not always receive live vaccines, which include polio; measles; measles, mumps, and rubella; rubella; and BCG. Some of these may be given when the child is in remission and has been off immunosuppressive treatment for more than six months. ${ }^{8}$ Individual evaluation is required by the specialist in charge.

(G) Such children constitute at most 3\% of a whole child population. ${ }^{12}$ Conventional practice is to protect these children from a febrile convulsion induced by the mild temperature experienced seven to 10 days after immunisation. This may be achieved by giving parents instruction on controlling temperature; including administration of paracetamol. 


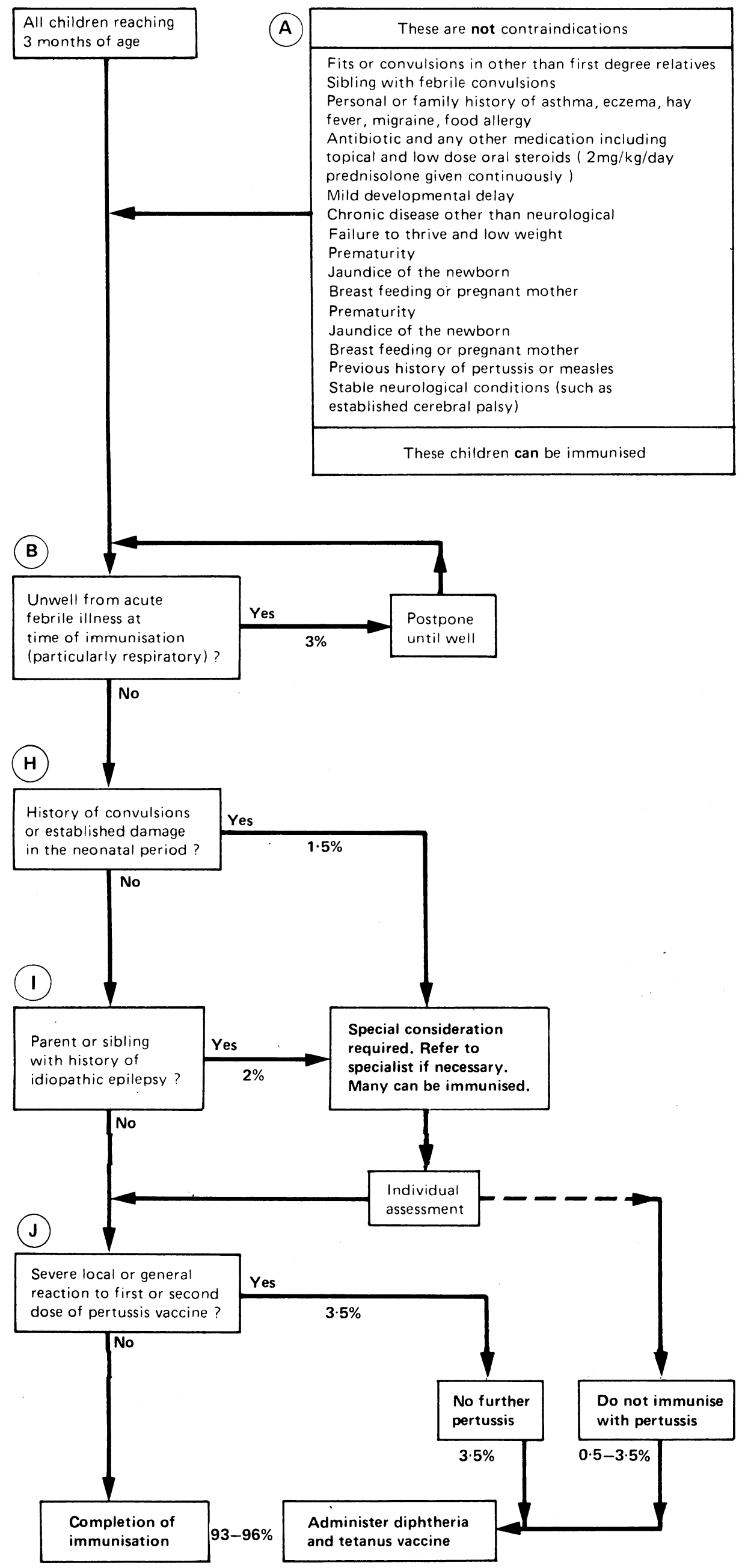

Triple vaccine

(A) All of these reasons have been presented to us as contraindications. None of them are, though some have been so in the past. They represent mythical contraindication $s^{i} 10$ by which many children are incorrectly denied protection.

(B) Children are sometimes thought to be too ill for immunisation. Children starting an acute febrile illness should have their immunisation deferred. ${ }^{x}$ To estimate the number of children affected we monitored three routine child health clinics (one in general practice, two organised by the health authority) during January to March 1986. On average $3 \%$ of children presenting for immunisation were too ill on the day.

(H) These are special considerations, not contraindications. Each child should be individually assessed. ${ }^{\times}$Infants with a history of convulsions will constitute up to $1 \%$ by the age at which three immunisations should have been given. ${ }^{13}$ We have estimated that another $0.5 \%$ of children with established cerebral damage should be included in this group. ${ }^{14} \mathrm{~A}$ child in this group should not be denied immunisation without specialist advice.

(I) These are special considerations, not contraindications. Children to whom they apply may be immunised but each case has to be individually considered. One survey has found that up to $3 \%$ of a child population would be included in such a category, ${ }^{12}$ though another study has estimated only $0.3 \%$ to $1 \%$ depending on age ${ }^{1+} \mathrm{A}$ child in this group should not be denied immunisation without specialist advice.

(J) These are true contraindications. ${ }^{*}$ Mild reactions, however, are common and normal. The definition of severe reactions is as follows. ${ }^{x}$

Local: An extensive area of redness and swelling which becomes indurated and affects most of the anterolateral surface of the thigh or a major part of the circumference of the upper arm.

General: A fever of over $39 \cdot 5^{\circ} \mathrm{C}$ within 48 hours of immunisation or any one of anaphylaxis, bronchospasm, laryngeal oedema, generalised collapse, prolonged unresponsiveness, convulsions, or prolonged inconsolable screaming occurring within 72 hours of immunisation.

With a much broader interpretation of the definition of a severe reaction $3.5 \%$ of children starting a course of pertussis vaccination might be expected not to complete for this reason. ${ }^{12}$ 